\title{
Mania in association with hydrocortisone replacement for Addison's disease
}

\author{
E. Ur, T.H. Turner' ${ }^{1}$ T.J. Goodwin², A. Grossman and G.M. Besser \\ Departments of Endocrinology and ${ }^{1}$ Psychological Medicine, St Bartholomew's Hospital, London \\ ECIA $7 B E$, and ${ }^{2}$ Department of Medicine, Mount Vernon Hospital, Northwood, UK
}

\begin{abstract}
Summary: A 32 year old woman with untreated primary adenocortical insufficiency presented with prominent depressive symptoms. Upon treatment with physiological doses of glucocorticoids she developed a self-limiting acute manic illness. We suggest that up-regulation of hippocampal glucocorticoid receptors as a consequence of prolonged hypocortisolaemia resulted in increased cerebral sensitivity to exogenous corticosteroids, which are known to precipitate manic symptoms in some normal individuals when given in supraphysiological doses.
\end{abstract}

\section{Introduction}

The occurrence of psychological symptoms in Addison's disease is well recognized and has formed the basis for a number of studies. These have concentrated on the presenting features. In Addison's original study, ${ }^{1}$ patients with adrenal insufficiency were described as having 'an inability to concentrate, drowsiness, restlessness, insomnia, irritability, apprehension and disturbed sleep.'

Engel and Margolin's study ${ }^{2}$ of 25 Addisonian patients revealed 16 with significant psychiatric symptoms, Of these, 3 were psychotically depressed and a further 6 were severely depressed. Other studies confirmed these findings. ${ }^{3}$ Symptomatic improvement has depended upon hydrocortisone replacement and has not been shown to occur after correction of attendant electrolyte deficit alone. ${ }^{3}$ There are only 2 reports in the literature of psychiatric reaction to treatment. Foerster ${ }^{4}$ has described an acute confusional state in a patient treated for Addison's disease with physiological replacement doses of hydrocortisone. Belchetz ${ }^{5}$ provides a short report of 1 patient with Addison's disease who repeatedly became unmanageably paranoid on commencement of hydrocortisone replacement. However, he gives no details of hydrocortisone dosage and its adequacy or of the patients premorbid and morbid mental state. Given the well-known association between hypercortisolaemia and psychological illness, the best known example of which is the 'steroid psychosis' associated with the administration of supra-

Correspondence: E. Ur, M.B., M.R.C.P.

Accepted: 10 June 1991 physiological doses of exogenous steroids, ${ }^{6,7}$ it may seem surprising that the transient relative hypercortisolaemia experienced by patients at the beginning of treatment for adrenal insufficiency has not led to any reports of significant psychiatric disorder. We report the first description of a case of an acute manic illness in the context of hydrocortisone replacement for Addison's disease.

\section{Case history}

The patient, a 32 year old teacher, was admitted to Mount Vernon Hospital with a 2 week history of vomiting and lethargy. She had been unwell for over 6 months with a history of progressively worsening depression. She complained of weight loss of over 1 stone, loss of concentration, lassitude, and an inability to work. Depression had been diagnosed and she was started on amitriptyline $50 \mathrm{mg}$ nocte but made no improvement and began to develop abdominal pain associated with nausea and vomiting. There was no family history of any autoimmune or endocrine disorders. Her father had suffered from depression in the past. There was no personal past psychiatric history. Her premorbid personality was described as friendly and outgoing although prone at times to anxiety and excessive brooding. Her marriage was described as happy by both partners.

At presentation in casualty she was shocked, dehydrated and unwell. Her blood pressure was $100 / 70 \mathrm{mmHg}$ recumbent and $70 / 0 \mathrm{mmHg}$ standing. Her pulse was $100 / \mathrm{min}$. She has marked pigmentation of skin, palmar creases and buccal 
mucosa. Mental state examination revealed a lethargic woman who was fully oriented in all modalities. Attention, concentration and memory were all unimpaired. Her verbal responses were slow but accurate. She was tearful and anxious, but there was no evidence of any significant mood disturbance, delusions or hallucinations. Preliminary investigations showed: plasma sodium $107 \mathrm{mmol} / \mathrm{l}$, potassium $5.0 \mathrm{mmol} / \mathrm{l}$, glucose $3.4 \mathrm{mmol} / 1$, and serum cortisol $<50 \mathrm{nmol} / 1$ (NR 0900h 250-650). Chest, skull, and abdominal $\mathrm{X}$-rays were all normal.

In view of these findings a provisional diagnosis of Addison's disease was made. Rehydration was commenced with 1 litre of $1.8 \% \mathrm{~N} /$ saline 8 hourly. A short Synacthen test ${ }^{8}$ next morning showed no cortisol response (all values pre- and post-ACTH $<50 \mathrm{nmol} / \mathrm{l}$ ) consistent with primary adrenocortical failure. The patient was commenced on intramuscular hydrocortisone $100 \mathrm{mg} 6$ hourly, which she had for $24 \mathrm{~h}$ before starting oral replacement therapy with hydrocortisone $20 \mathrm{mg}$ in the morning and $10 \mathrm{mg}$ in the evening, and fludrocortisone $50 \mu \mathrm{g}$ in the morning and the evening.

She made a rapid clinical improvement on this regimen and within $48 \mathrm{~h}$ her electrolytes had become normal. Thirty-six hours after starting oral replacement therapy, and despite the improvement in her physical condition and blood picture, she began to develop prominent psychiatric symptoms. She complained initially of being unable to sleep, with racing thoughts which she could not control, and saw 'angels floating in the air'. She was fully oriented to time, place, person and event, but was over-talkative and easily distractible. Her speech was loose in association, over-detailed and difficult to follow, showing pressure and flight of ideas. She was disinhibited and over-familiar. Her gestures were exaggerated and persisted despite physical fatigue. The psychiatric diagnosis was mania and she was given pimozide $4 \mathrm{mg}$ orally, once daily. The Manic Rating Scale (MRS) ${ }^{9}$ was used to monitor her progress. At the onset of her psychiatric symptoms, on the third day after admission, her MRS score was 38 . Over the following 2 weeks her mental symptoms subsided with a MRS score of 15 at day 8 and 4 at day 15 . The pimozide was gradually reduced and then withdrawn. Sampling of blood throughout the day for serum cortisol on the hydrocortisone replacement therapy (hydrocortisone day curve) was performed on day 13 , confirming that replacement therapy was adequate.

She was discharged home well after 3 weeks. At 6 months follow-up she was physically well and had made a full return to work and all her other activities. Neither she nor her husband reported any relapse in her mental symptoms. Her MRS score was 1 .

\section{Discussion}

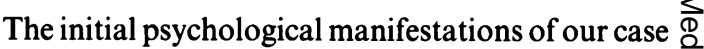
fit in with previously published findings, but the $c$. development of an acute manic psychosis in the $\vec{F}$ context of physiological corticosteroid replace- $\stackrel{0}{+}$ ment is unusual. The only detailed report of $\frac{}{C}$ psychiatric reaction to replacement therapy in $\overline{\bar{\sigma}}$. Addison's disease described an acute confusional $\frac{\sigma}{\sigma}$ state. ${ }^{4}$ In our case clear consciousness was pre- $\stackrel{\varnothing}{\varrho}$ served at all times, in the context of classical manic is symptoms. There are several possible explanations $\overrightarrow{0}$ for our patient's psychiatric disturbance. The first postulates a purely psychological mechanism $\vec{\omega}$ whereby the stress of a physical illness triggers acute mania in a predisposed individual. It would $\stackrel{0}{\circ}$ be difficult to exclude this, but there is no support- 3 . ing evidence in the form of any past history of $\infty$ psychiatric disorder or emotional maladaptation. It is also possible that the electrolyte disturbance on per se, and more specifically the rapid change in $\vec{A}$ electrolyte balance during the initial treatment 을 phase, could underlie the psychological symptoms, and indeed there is strong evidence linking electro- $c$ lyte disturbances with psychological symptoms and psychiatric illness. ${ }^{10}$ However, the acute episode in this patient began $24 \mathrm{~h}$ after her electrolytes had been normalized and persisted for 2 more weeks despite a stable electrolyte balance.

Manic symptoms are a prominent feature of the classical 'steroid psychosis' which occurs during the therapeutic administration of supraphysiological doses of corticosteroids ${ }^{7}$ and in Cushing's syndrome. ${ }^{11}$ The mechanism underlying this $\stackrel{\varnothing}{\varnothing}$ phenomenon is poorly understood. There are sug- $\vec{F}$ gestions in the literature that these mental changes are indirectly due to the amelioration of the physical symptoms of concomitant organic disease rather than any primary psychotropic action of steroids. ${ }^{12}$ Excess glucocorticoids have been shown to decrease the amplitude of visual evoked potentials and to lead to disturbances in the detection 3 . and interpretation of sensory stimuli. ${ }^{13}$ Conversely, 8 lower thresholds have been demonstrated for $₹$ various sensory pathways in cortisol deficient $O$ patients, and these abnormalities have been corrected by cortisol replacement. In this context, o Carpenter and Gruen ${ }^{14}$ have hypothesized a link between dysphoric mood and disordered inform- $\sigma$ ation processing. However, our patient was receiv- $N$ ing physiological doses of corticosteroid. We $\underset{\mathrm{N}}{\mathrm{N}}$ would therefore postulate the possibility in this patient of an increased sensitivity of neural glucocorticoid receptors generated by the pro- $\frac{\mathscr{\Phi}}{\Phi}$ longed hypocortisolaemia. The response to $\stackrel{0}{?}$ physiological doses of corticosteroids in such a situation would be supraphysiological.

There has been considerable interest in the molecular biology of corticosteroid action on the 
brain, particularly with regard to the interaction with receptor systems. Studies in rats reveal the presence of cerebral glucocorticoid receptors ${ }^{15}$ (GR) which mediate feedback action of corticosterone on stress-activated brain processes. A number of behavioural effects of corticosteroids have been attributed to their action via GR receptors. ${ }^{16}$ These include effects on sleep ${ }^{17}$ the detection and perception of sensory stimuli, ${ }^{11}$ food intake, ${ }^{18}$ and affect. ${ }^{19}$ Of particular note is the fact that GR receptors are subject to auto-regulation. Thus, adrenalectomy results in up-regulation of GR receptors (increased activity or numbers of receptors)..$^{14}$

Thus, it is our contention that in untreated Addison's disease, prolonged hypocortisolaemia

\section{References}

1. Addison, T. On the Constitutional and Local Effect of the Suprarenal Capsules. S. Highley, London, 1855.

2. Engel, G.L. \& Margolin, S.G. Neuropsychiatric disturbances in Addison's disease and the role of impaired carbohydrate in the production of abnormal cerebral function. Arch Neurol Psych 1941, 45: 881-884.

3. Cleghorn, R.A. Adrenal cortical insufficiency: psychological and neurological observations. Can Med Assoc J 1951, 65: 449-454.

4. Foerster, K. Akutes delirantes Syndrom bei Morbus Addison unter Cortison-Substitutionstherapie. Nervenarzt 1976, 47: 124-125.

5. Belchetz, P. Endocrine emergencies. In: Milo Keynes, W. \& Fowler, P.B.S. (eds) Tutorials in Post Graduate Medicine. Clinical Endocrinology. Heinemann, London, 1984, pp. 603-634.

6. Glaser, G.H. Psychotic reaction induced by corticotrophin (ACTH) and cortisone. Psychosom Med 1953, 15: 280-291.

7. Ling, M.H.M., Parry, P.J. \& Tsuan, M.T. Side effects of corticosteroid therapy. Arch Gen Psych 1981, 38: 471-477.

8. Galvao-Teles, A., Burke, C.W. \& Russell Fraser, T. Adrenal function tested with tetracosactrin depot. Lancet 1971, i: 557-560.

9. Young, R.C., Biggs, J.T., Zeigler, V.E. \& Meyer, D.A. A rating scale for mania: reliability validity and sensitivity. $B r J$ Psych 1978, 133: 429-435.

10. Maas, J. Adrenocortical steroid hormones, electrolytes and the disposition of the catecholamines with particular reference to depressive states. J Psychiat Res 1972, 9: 227-241. leads to up-regulation of central GR receptors. As a consequence of this, treatment with physiological doses of glucocorticoid elicits a supraphysiological response in neural pathways which are subject to GR receptor-mediated glucocorticoid modulation. Exposure to replacement doses of hydrocortisone eventually down-regulates receptor activity or number so that the supraphysiological response is self-limiting and the psychiatric reaction remits. It is somewhat surprising that this phenomenon has not been previously reported in the literature. This may be a reflection of the rarity of the condition, and the masking of manic symptoms by the debilitating nature of the illness. Clearly, there is a continuing need for detailed mental state assessment of patients with endocrine disorders.

11. Jeffcoate, W.F., Silverstone, J.T., Edwards, C.R.W. \& Besser, G.M. Psychiatric manifestations of Cushing's syndrome: response to lowering of plasma cortisol. $Q J$ Med 1979, 191: 465-472.

12. Mitchell, D.M. \& Collins, J.V. Do corticosteroids really alter mood? Postgrad Med J 1984, 60: 467-470.

13. Henkin, R.I. The effects of corticosteroids and ACTH on sensory systems. Prog Brain Res 1970, 32: 270-293.

14. Carpenter, W.T. \& Gruen, P.H. Cortisol's effects on human mental functioning. J Clin Psychopharm 1982, 2: 91-101.

15. De Kloet, E.R. \& Reul, J.M.H. Feedback action and tonic influence of corticosteroids on brain function: a concept arising from the heterogeneity of brain receptor systems. Psychoneuroendo 1987, 12: 83-105.

16. De Kloet, E.R., Veldhuis, H.D., Wagenaars, J.L. \& Bergink, E.N. Relative binding affinity of steroids for the corticosterone receptor system in the rat hippocampus. J Steroid Biochem 1984, 21: 173-178.

17. Gillin, J.C., Jacobs, L.S., Fram, D.H. \& Synder, F. Acute effect of a glucocorticoid on normal human sleep. Nature 1972, 237: 398-399.

18. Liebowitz, S. \& Roland, C.R. Noradrenergic feeding elicited via the paraventricular nucleus is dependent upon circulating corticosterone. Physiol Behav 1984, 32: 857-864.

19. von Zerssen, D. Mood and behavioural changes under corticosteroid therapy. In: Itil, T.M., Laudahn, G. \& Herrmann, W.M. (eds) Psychotropic Action of Hormones. Spectrum, New York, 1972, pp. 195-222. 